\title{
Developing Collaboration as a Transferrable Skills in Biology Tertiary Education
}

\author{
Torstein Nielsen Hole \\ University of Bergen, Norway
}

\begin{abstract}
Transferable skills as a concept in tertiary education has received increased interest since the Bologna process and through developments in the work market. The concept as a learning goal is seen as a means for ensuring employability in a changing industrial economy as well as increasing legitimacy of skills that are desirable across different disciplines.

In this paper I will present some means to develop legitimacy in transferable skill learning in discipline education in general and biology education specifically. A concrete focus is collaboration, which functions as an example of how the intangible nature of some educational goals requires a theoretical response. This is performed on the basis of theoretical conceptions about tacit and work-place learning.
\end{abstract}

\section{Introduction}

Interest in transferrable skills have emerged thought the 2000s in Europe, especially in conjunction with the Bologna-process [1]. Traditional University disciplines are distinct in that the main goal of these courses is not to prepare candidates for a specific career, but to make candidates well-versed, and often experts in a specific field. However, industry demands gives rise to an increased emphasis on skills that enable candidate flexibility in work, and transferability across occupational disciplines. In the following, theoretical perspectives are presented to look further at promoting and legitimizing these skillsets in biology education. The perspectives are both representations of learning strategies and touches a discussion about discipline-based and profession based educations. Two different traditions that have traditionally stood apart, however, several tendencies seem to point towards an increased interrelationship both in strategies and research.

In the case of biology education in Norway, the Centre for Excellence in Biology Education (bioCEED) initiative looks closer at the development of transferable skills, deeming practical skills to be "one of the domains of biology" [2].

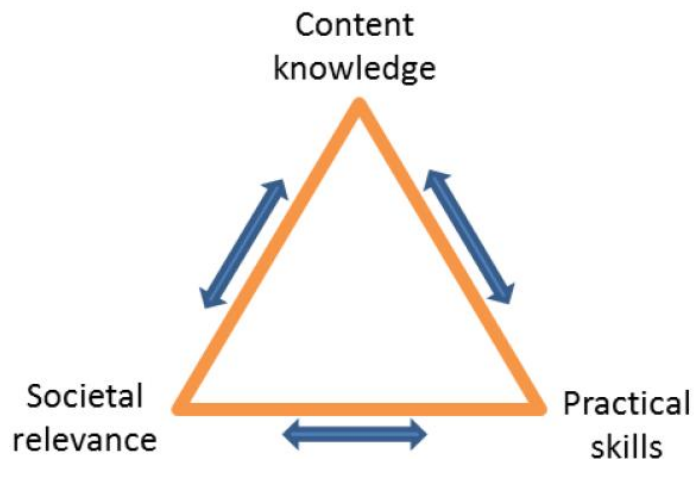

Figure 1: The domains of biology [2]

One of the goals is to uncover some of the sentiments regarding transferrable skills in discipline education, and to move further in uncovering the case of collaborative skills. Tentatively, both educators and students deem transferrable skills to be important to educational success, which also coincides with employers' demands for skills [3]. Transferable skills can be argued to fit into the above model across all domains. In the following, I will argue how cultivation of content knowledge, practical skills and societal relevance all can have a relationship with students' learning of transferable skills. The basic legitimization of these domains of biology has also been emphasized by the American Association for the Advancement of Science (AAAS) [4] by highlighting how for instance "the growing complexity of the data generated and the need for computational and modeling skills to deal with that complexity"; increased complexity should precipitate an emphasis on core scientific skills that enhance candidates' ability to critically use and handle change. In this context societal competence also becomes important, because candidates need to be able to critically review their own role in societal transformation.

\section{Determining learning of transferable skills}

Transferrable skills can take many forms, and narrowing down all the forms can in itself be controversial [5]; a EU-commission report has 
attempted to categorize skills into hard and soft skills that require more or less sophisticated skill-sets and experience to master [1]. The report goes further to address degrees of transferability, i.e. "[transferable skills] are skills applicable to different tasks and jobs for which the level of applicability varies according to economic, legislative, geographic and other contexts. The more general the skill is, the more transferable it is and vice versa" (p. 9). This highlights how transferable skills are associated with process rather than result; common examples of transferable skills are digital proficiency, writing, analysis and collaboration. All of which are general skills that are developed continuously. This understanding of skills seems to coincide with Eraut's [6] concept about learning trajectories. Trajectory means learning of skills is seen as a continuous process that is not completed at a particular point, but rather arrested, halted or accelerated at different points and during different circumstances. In such an understanding of transferable skill learning, the mastery of for instance digital skills is developed by the individual continuously, and at different points of time the individual will develop these skills more than during other times.

Another way to narrow transferable skills is into i) technical and ii) intrapersonal or intangible skills. In biological training, candidates are educated in numerical skills (i.e. statistics) and technical skills in the lab which can be considered transferable across fields. While other skills, which might be dubbed intangible or intrapersonal, such as collaboration, presentation and communication are another [5].

Transferable skill training in higher education in biology takes place across different circumstances. Transferable skills are at times directly related to the ability to master a discipline and other times more loosely associated with it. Computation and literacy are skills the candidate develops throughout experiential activity; however, other skills such as lab-work are less transferable. The candidate cultivates theses skills across different activities, some more than other. The skills are also deeply dependent on the circumstances of the candidates' learning.

\section{Learning collaboration as a transferable skill}

The previously mentioned AAAS summary [4] juxtapose collaborative skills with fundamental scientific skills such as computational analysis and critical reading (literacy). It is noteworthy how this is deemed a skill that is put front and center in developing scientific literacy. The basis of the assertion rests on both the ability to disseminate knowledge and to collaborate with others in the developing new knowledge.

Collaborative skills can be viewed both as a component in sociocultural conceptions of learning, in that the learning process is dialogic and therefore enhanced when collaboration is promoted (see for instance Wertsch [7]), and is in itself a necessary skill in most lines of work. Additionally, collaboration requires activity - in a bid to move from student passivity to student activity in their learning there is a further reason to look at this skill.

Collaboration in higher education is often promoted through group activities such as collaborative student papers, lab-work or field work. It is interesting to note here that a significant part of the university-driven promotion of collaboration has a practice component. For instance, Lave [8] deems that the learning process that develops through communities of practice is a learning strategy with great potential. However, it seems that a large part of the curricular component of transferable skills come about as an afterthought or as a result of discipline training rather than as the result of concerted effort [5]. Tentatively, clearer distinctions about the merits and methods to facilitate transferrable skills in individual courses may be warranted.

Other research has highlighted the need for concerted efforts in enhancing transferable skills among students $[9,10]$, as well as the work-place demand for them, specifically in biology-related disciplines [11].

There are three potential avenues of knowledge gathering concerning collaboration in transferrable skills in discipline education: The mode of collaboration in field work, the whys and the hows. 2. The mode of collaboration in campus-based work. 3 . The mode of collaboration in practice, i.e. outsidecampus work in biology. At this point there is a need to investigate whether the collaborative mode has implications for discipline learning (and excellence), if the skills increase students belonging or motivation to follow the courses and whether it increases students' employability.

Scholz et al.'s [12] study on transferable skills among students in environmental studies in Switzerland maps some conceptions among workplace supervisors and students learning outcomes. The study seems to hold that students acquire a plethora of skills. Their study is built upon a description of transferable skills divided among "general skills and abilities" which are determined to be "working in a group, planning abilities, computer skills and languages, writing skills and presentation skills".

Collaboration is therefore a transferable skill that develops as a process, and across different courses, 
though often as an afterthought rather than a planned learning activity. In the following I will discuss how concerted effort can be pursued through work-place practice and experiential activity.

\section{Activity as learning}

A mutual relationship between work and learning has a long-standing tradition in western society. One basis for this conception is Dewey's [13] emphasis on learning through activity and the interchangeable relationship between abstract subject matter and the individual's ability to carry out manual actions on the basis of internalized knowledge.

However, the learning that occurs in activity is also a distinct learning process in itself. Polanyi [14] holds that several aspects of human activity is difficult to describe through textual means because of the myriad of action the individual takes.. Eraut [15] develops this discussion with the issue of determining knowledge that transcends formalized categorization. Eraut argues that knowledge can be categorized as personal or codified in that some forms of knowledge is codified by critical review or concrete demands of schools, universities or work-places, but personal forms of knowledge are often more intangible. Personal knowledge arises in the individual through uncounted means, sometimes through formal settings i.e. lectures and reading with an assessment through examination, and through informal means such as activity and experiential activity. The former can normally be associated with campus-lectures and the latter with workplace learning.

\section{Developing transferable skill learning through practical work}

A conception of learning as a personal process entails that development of competencies (learning) takes place across formal, campus-based work that is codified, but that a substantial part of learning occurs in non-codified settings. Billett [16] points to the possibility of workplace learning as a learning strategy with great potential. This form of knowledge has long traditions in vocational disciplines and in professional academic fields, for instance in medicine and teaching. The work-place learning is codified (integrated in coursework) for candidates in these fields. Typically, this is performed through an inwork learning strategy for career preparation for distinct skills that are closely tied up with their chosen field. An example of this is classroom leadership and patient interaction; both are skills that are only seen as acquired after extensive practical training.

Implicit in work-place learning strategy is an understanding that development of these skills to a sufficient level requires on-the job training. A professional perspective on work-place learning is often concerned with the intricacies of learning a trade, and that mastery of the trade comes about during practical learning [17]. However, practice as a legitimate learning strategy does not exclude transferable skills from being among the skill-sets candidates attain through work-place learning.

Schön's [17] concepts of a chaotic "swamp" as the professional practice and the "plateau" as the abstract and normative description of professional practice displays how experiential learning is an integral part of candidates' learning. However, these learning strategies are useful to consider in nonprofessional disciplines as well. Scholz et al.'s [12] study for instance shows that useful skills are enhanced among biology students in internship practice. Goodenough et al. [18] show that practice activity in field trips enhance students' biology content knowledge. Both studies show how collaboration is a particularly prominent skill in practice learning.

On the basis of these points an effort to develop transferable competencies in work-place contexts seem warranted. Bennett [10] has developed a model for identifying knowledge provisions in higher education where workplace learning is put in a relationship with discipline knowledge and transferable skills. Bennett holds that different learning activities emphasize different domains, for instance that learning outcomes associated with workplace experience and skills are linked with one particular learning activity while workplace knowledge and content knowledge can be associated with another. Consecutively, content knowledge and transferable skills are developed through other activities; i.e. reading, laboratory work or lectures. Through theoretical perspectives such as Bennett and Eraut's conceptions of knowledge we can approximate how transferable skills are developed through work: i) Bennett's model highlights the specific categories of learning that arises in concrete learning situations, ii) Eraut describes potential results (personal or codified). Biology students are subject to both learning in the field and laboratory-work, with the inclusion of workplace learning we are legitimizing different forms of knowledge. Both i) and ii) arise through candidates' activity over time, and at varied intensity as Eraut's learning trajectory presupposes [6]. 


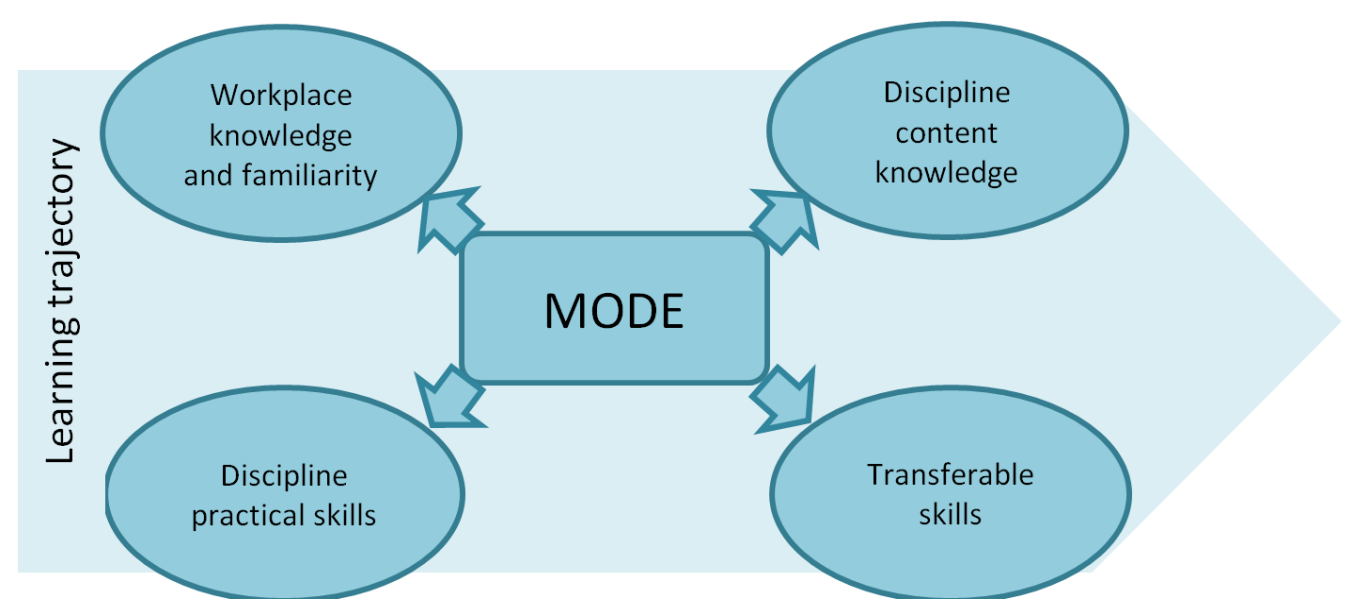

Figure 1: Conceptual model of modes of learning across candidates' learning trajectories

The above model is an attempt to conceptualize student's learning trajectories with respect to candidates' modes of learning. Mode is meant to encompass different activity which influences different domains of learning. For instance, students' activity in field work can shape students' discipline practical skills through increased knowledge about biological phenomena and also increase students' disciplinary practical skills that are specific to biology. Consecutively, workplace-practice where the student is required to collaborate can shape candidates' perceptions about their personal identity as a biologist (workplace knowledge and familiarity), as well as giving the candidate experience with the transferable skill of collaboration. Different modes can affect different domains at different points of time, sometimes not at all while some times all points simultaneously. The proposed model is based on a biological academic context, hence the clear emphasis on practical skills which might not be as prominent in other disciplines. With alterations the model can be applicable across disciplinary fields.

Through different perspectives we can reasonably assert that learning and work is intertwined, it should therefore follow that work and transferable skills are integral pieces of a candidate's academic development that should be pursued further in curricular development.

\section{Conclusions}

Work and learning has a basic relationship that has both be subject to different perspectives in research and is an integral part in several codified learning contexts across the modern economy. Increased emphasis on transferable skills also actualizes emphasis on work training with an explicit emphasis on transferable skill training. The case is made that practical training is an important and valid educational strategy for an academic discipline as biology.

In order to investigate the relationships between work and transferable skills further, more knowledge about the merits of collaboration needs to be determined. Survey of biology students and lecturers might provide some clues, but further research should also try to increase available understanding about how collaboration functions, specifically in distinct modes such as during field-work or lab-work.

Further, work training has a long standing tradition as a learning strategy. Increased interest in careers among students and governmental bodies must be responded to on the basis of knowledge about learning and development. Current practices would be remiss to avoid utilizing these avenues of development.

\section{Reference}

[1] European Comission, Transferability of skills across economic sectors, editor: Z. Karásek, Publications Office of the European Union, Luxembourg, 2011.

[2] BioCEED, BioCEED - Centre of Excellence in Biology Education, NOKUT, Oslo, 2013.

[3] R. Bennett, "Employers' Demands for Personal Transferable Skills in Graduates: a content analysis of 1000 job advertisements and an associated empirical study", Journal of Vocational Education \& Training, 2002. pp. 457476.

[4] T. Woodin, V.C. Carter, and L. Fletcher, "Vision and Change in Biology Undergraduate Education, A Call for Action-Initial Responses", CBE-Life Sciences Education, 2010, pp. 71-73.

[5] D. Bridges, "Transferable skills: A philosophical perspective", Studies in Higher Education, 1993, pp. 43-51. 
[6] M. Eraut, Knowledge, Working Practices, and Learning, in Learning Through Practice, Editor: S. Billett, Springer, Netherlands, 2010, pp. 37-58.

[7] Wertsch, J.V, Voices of the Mind, Harvard University Press, Cambridge, 1991.

[8] Lave, J. and E. Wenger, Situated learning: Legitimate peripheral participation, Cambridge University Press, Cambridge, 1990.

[9] I. Drummond, I. Nixon, and J. Wiltshire, "Personal transferable skills in higher education: the problems of implementing good practice", Quality Assurance in Education, 1998, pp. 19-27.

[10] N. Bennett, E. Dunne, and C. Carré, "Patterns of core and generic skill provision in higher education". Higher Education, 1999, 71-93.

[11] J.L. Blickley, et al., "Graduate Student's Guide to Necessary Skills for Nonacademic Conservation Careers", Conservation Biology, 2013, pp. 24-34.

[12] R.W. Scholz, R. Steiner, and R. Hansmann, "Role of internship in higher education in environmental sciences", Journal of Research in Science Teaching, 2004, pp. 24-46.

[13] Dewey, J, Democracy and Education, Simon \& Brown, Hollywood, 2011 ed.

[14] Polanyi, M, The Tacit Dimension, University of Chicago Press, Chicago and London, 2009.

[15] M. Eraut, "Non-formal learning and tacit knowledge in professional work", British Journal of Educational Psychology, 2000, pp. 113-136.

[16] S. Billett, "Integrating learning experiences across tertiary education and practice settings: A socio-personal account", Educational Research Review, 2014, pp. 1-13.

[17]Schön, D.A, Educating the Reflective Practitioner. Jossey Bass Publ., San Fransisco, 1987.

[18] A.E. Goodenough, et al., "The Role of Overseas Field Courses in Student Learning in the Bioscience", Bioscience Education, 2014, pp. 1-15. 